cannulation of the carotid artery can be performed on the right or left side in accordance with vascular pathology. ${ }^{1}$ If the proper flow in the carotid artery cannot be restored by arch repair, which can occur occasionally when the repair of a dissected innominate artery bifurcation is not possible, an aorta-carotid bypass may be necessary and easily performed with a carotid side-graft used for cannulation.

\section{References \\ 1. Urbanski PP. Carotid artery cannulation in acute aortic dissection with malperfu-} sion. J Thorac Cardiovasc Surg. 2006;131:1398-9.
2. Urbanski PP, Lenos A, Lindemann Y, Zacher M, Frank S, Diegeler A. Use of a carotid artery for arterial cannulation: side-related differences. Thorac Cardiovasc Surg. 2010;58:276-9.

3. Urbanski PP, Lenos A, Bougioukakis P, Neophytou I, Zacher M, Diegeler A. Mildto-moderate hypothermia in aortic arch surgery using circulatory arrest: a change of paradigm? Eur J Cardiothorac Surg. 2012;41:185-91.

4. Urbanski PP, Lenos A, Zacher M, Diegeler A. Unilateral cerebral perfusion: right versus left. Eur J Cardiothorac Surg. 2010;37:1322-36.

5. Orihashi K, Sueda T, Okada K, Takahashi S. Compressed true lumen in the innominate artery: a pitfall of right axillary arterial perfusion in acute aortic dissection. J Thorac Cardiovasc Surg. 2009;137:242-3.

6. Minatoya K, Ogino H, Matsuda H, Sasaki H. Rapid and safe establishment of cardiopulmonary bypass in repair of acute aortic dissection: improved results with double cannulation. Interact Cardiovasc Thorac Surg. 2008;7:951-3.

\title{
Lateral caval flap repair of adult sinus venosus atrial septal defect: A natural novel approach
}

\author{
Gurjyot Bajwa, MD, ${ }^{\mathrm{a}}$ Iva Dostanic-Larson, MD, PhD, ${ }^{\mathrm{b}}$ Richard A. Krasuski, MD, ${ }^{\mathrm{c}}$ and \\ Gosta B. Pettersson, MD, PhD, ${ }^{\mathrm{a}}$ Cleveland, Ohio
}

Ten percent of atrial septal defects (ASD) are sinus venosus ASDs associated with partial anomalous pulmonary venous connection, with one or more veins from the right upper lobe entering the lateral aspect of the superior vena cava (SVC). Repair thus involves ASD closure and rerouting of the anomalous pulmonary veins to the left atrium. Surgical repair techniques include single patch, double patch, and Warden procedures, all of which require incisions or suturing in the right atrium that could interfere with the blood supply to the sinus node or directly injure the sinus node and expose the left atrium to a nonendothelialized patch. Although unusual, reported complications include sinus node dysfunction, pulmonary vein obstruction, and baffle thrombosis and embolic events. ${ }^{1-4}$ Owing to ASD location and anomalous veins, device closure is not an option.

We describe a novel approach using the lateral wall of the SVC as a flap to baffle the anomalous veins to the ASD, combined with an autologous pericardial patch to close

From the Department of Thoracic and Cardiovascular Surgery, ${ }^{\mathrm{a}}$ Heart and Vascular Institute; Cleveland Clinic Lerner College of Medicine ${ }^{\mathrm{b}}$; and Department of Cardiovascular Medicine ${ }^{\mathrm{c}}$ Heart and Vascular Institute, Cleveland Clinic, Cleveland, Ohio.

Disclosures: Authors have nothing to disclose with regard to commercial support.

Accepted for Presentation on Demand (POD) electronic presentation at the 92nd Annual Meeting of The American Association for Thoracic Surgery, San Francisco, California, April 28-May 2, 2012.

Received for publication March 20, 2012; revisions received April 25, 2012; accepted for publication May 16, 2012; available ahead of print June 18, 2012.

Address for reprints: Gosta B. Pettersson, MD, PhD, Cleveland Clinic Foundation, 9500 Euclid Ave, Mail Code J-41, Cleveland, OH 44195 (E-mail: petterg@ccf. org).

J Thorac Cardiovasc Surg 2012;144:984-5

$0022-5223 / \$ 36.00$

Copyright (c) 2012 by The American Association for Thoracic Surgery

http://dx.doi.org/10.1016/j.jtcvs.2012.05.048 and augment the lateral SVC defect without exposing the left atrium to a nonendothelialized patch.

\section{PATIENTS AND METHODS}

From January 2000 to June 2010, 32 consecutive patients underwent surgical repair of sinus venosus ASD with anomalous pulmonary veins with lateral caval flap. Mean age was 48 years (range, 26-74 years); 14 were men and 18 women. Available preoperative and postoperative electrocardiograms were reviewed. The Social Security Death Master File was used to assess late mortality, and follow-up was obtained using a questionnaire approved by the Institutional Review Board of the Cleveland Clinic, with mean follow-up of approximately 60 months.

\section{OPERATIVE TECHNIQUE}

Intraoperative transesophageal echocardiography was performed. An upper partial ministernotomy was used for isolated procedures and those combined with patent foramen ovale closure (12 patients), and full sternotomy was used for combined procedures (20 patients). The SVC was cannulated well above the highest anomalous vein, which always entered below the azygos vein (Figure 1, A). A small high atriotomy was performed to confirm morphologic features and for placement of the retrograde cardioplegia cannula. The SVC was incised 2 to $3 \mathrm{~mm}$ behind the sinus node (Figure 1,B). The created flap was sutured to the caval wall and the rim of the ASD to create an unobstructed tunnel, routing the anomalous pulmonary veins to the ASD (Figure 1,C). A generous pericardial patch was harvested to reconstruct and augment the SVC (Figure 1, D). Suturing required that fine superficial bites be taken at the flap-pulmonary vein junction and stay in the endocardium behind the sinus node (Figure 1,E). All suture lines were performed with running 5-0, 6-0, or 7-0 monofilament sutures, depending on structure size and quality. 


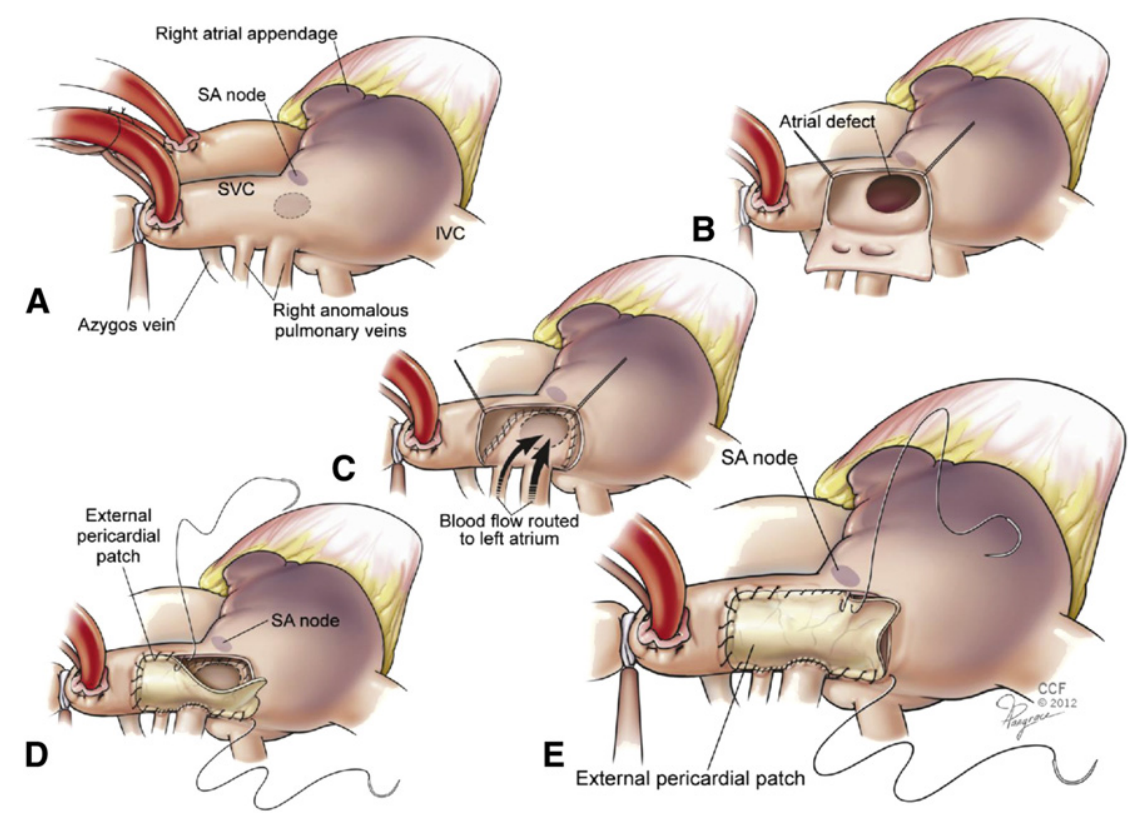

FIGURE 1. A-E, Sinus venosus atrial septal defect with anomalous right upper pulmonary veins (A). A lateral caval flap is mobilized and sutured to reroute the anomalous venous return to the left atrium through the atrial septal defect (B and C). An autologous pericardial patch is used to close and augment the superior vena cava. Notice the fine bites taken in the pulmonary veins and endocardium behind the sinoatrial node (D and E). IVC, Inferior vena cava; $S A$, sinoatrial node; $S V C$, superior vena cava.

\section{RESULTS}

Of the 32 patients, 21 had a concomitant procedure: coronary artery bypass grafting, maze, tricuspid valve repair, mitral valve repair, pericardiectomy, or patent foramen ovale closure. There were no residual ASDs. No patient had stenosis of either the redirected anomalous pulmonary veins or the SVC develop. No patient has required reoperation. There have been no early or late deaths.

Comparison of preoperative and postoperative electrocardiograms of the 29 patients who were in sinus rhythm preoperatively showed junctional rhythm in 1 postoperatively; 28 remained in sinus rhythm. Among 3 patients in atrial fibrillation preoperatively, 1 converted to sinus rhythm postoperatively after a maze procedure.

\section{COMMENT}

In adults, the lateral caval flap repair is natural and creates an unobstructed tunnel with an endocardial surface rerouting the anomalous veins to the left atrium. Our attention to the area of the sinus node has led to excellent freedom from atrial dysrhythmias. The patient in whom junctional rhythm developed after the procedure did not require a pacemaker. No sinus node artery was divided in any of these cases.

In adult patients, the lateral caval flap approach is technically appealing and simple, particularly when the anomalous pulmonary vein(s) and the sinus venosus ASD are in favorable relation to each other.

In memory of Iva Dostanic-Larson who started this study as a medical student.

\section{References}

1. Stewart S, Alexson C, Manning J. Early and late results of repair of partial anomalous pulmonary venous connection to the superior vena cava with a pericardial baffle. Ann Thorac Surg. 1986;41:498-501.

2. Gustafson RA, Warden HE, Murray GF, Hill RC, Rozar GE. Partial anomalous pulmonary venous connection to the right side of the heart. $J$ Thorac Cardiovasc Surg. 1989;98:861-8.

3. Attenhofer Jost CH, Connolly HM, Danielson GK, Bailey KR, Schaff HV, Shen WK, et al. Sinus venosus atrial septal defect: long-term postoperative outcome for 115 patients. Circulation. 2005;112:1953-8.

4. Agnoletti G, Iserin L, Boudjemline Y, Mousseaux E. Stroke after surgical treatment of sinus venosus type atrial septal defect: percutaneous treatment. Int $J$ Cardiol. 2007;119:e40-2. 